\title{
The Winged: An Upper Missouri River Ethno-ornithology. By Kaitlyn Moore Chandler, Wendi Field Murray, María Nieves Zedeño, Samrat Miller Clements, and Robert James. 2017. The University of Arizona Press, Tucson. 129 pp.
}

\author{
David A. Hooper ${ }^{1 *}$ \\ ${ }^{1}$ Department of Anthropology, University of Montana, Missoula, USA. \\ *david1.hooper@umontana.edu
}

Received June 7, 2019

OPEN ひACCESS

Accepted July 8, 2019

DOI 10.14237/ebl.10.1.2019.1604

Published August 6, 2019

Copyright (c) 2019 by the author(s); licensee Society of Ethnobiology. This is an open-access article distributed under the terms of the Creative Commons Attribution-NonCommercial 4.0 International Public License (https://creativecommons.org/licenses/by-nc/4.0), which permits non-commercial use, distribution, and reproduction in any medium, provided the original author and source are credited.

The Winged: An Upper Missouri River Ethno-ornithology is a product of research aimed to inform land managers about the relationships between Native Americans and birds of the northern watershed of the Missouri River. The authors use a relational framework to produce an "anthropological inquiry into the society of people and birds." After the introductory chapter, chapter two describes the geography and ethnic groups of the Upper Missouri. The authors' research focused on the Blackfoot, Assiniboine, Mandan, Hidatsa, Arikara, and Crow nations. The rest of the book addresses seven themes: what are birds' roles in creation stories; the qualities of birds; birds as messengers; imagery of birds; birds' role in material culture; and hunting/trapping of birds.

Throughout, the authors successfully connect previously discussed aspects of birds to the current topic. The connection of eagles to thunder gods is discussed in chapter three, and in the following chapters that connection informs the understanding of eagles as messengers, their meaning in art, how their parts are used in ceremony, and how they are hunted. The authors' success in showing how traditional beliefs and stories inform other aspects of human-bird relationships is impressive.

The authors make good use of photos. There are 47 colored plates of the birds. Black and white photos of museum artifacts illustrate topics being addressed in the text.
One of the weaknesses of this volume is the authors' choice not to incorporate more natural history in their analysis. For example, in the section concerning bird qualities and horticulture, the authors write that

The term 'blackbird' probably refers to a host of different species that generally resemble one another, such as the Brewer's Blackbird (Euphagus yyanocephalus), the Common Grackle (Quisalus quiscula), and the Brown-headed Cowbird (Molothrus ater).

Earlier, the authors describe the role of generic blackbirds with successful horse raiding. Of the three species listed, Brown-headed Cowbirds are the only species that has a strong relationship with grazing mammals. This species is known to forage on insects disturbed by herding mammals. In addition, during the breeding season cowbirds will make daily trips between nesting sites and foraging areas (Scott et al. 1992). Therefore, it is likely that Brown-headed Cowbirds are the species associated with success in horse raiding. By incorporating more natural history they could have more thoroughly demonstrated how Indigenous knowledge, belief, and practices concerning birds have strong connections to observed phenomena.

One of the major claims of this book is that birds are culturally significant as messengers. This role is placed within a spiritual and symbolic perspective and 
exemplified through traditional stories. The presentation of how biology, ecology, or behavior connects to birds' roles as messengers is limited. A clear example of how bird behavior conveys messages is how, for the Mandan, Hidatsa, and Arikara, spring migration of water fowl, specifically Canada Goose (Branta canadensis), indicated when to plant, which reflects a correlation between spring migration and favorable conditions for successful agriculture. Other forms of communication are clearly more symbolic. According to many tribes, Black-billed Magpies (Pica budsonia) are the high god's messenger, because they often come near human habitations and overhear conversations. In my opinion, other examples of birds conveying information presented as symbolic are based on biology. For example, if American Robins (Turdus migratorius) and Meadowlarks (Sturnella spp.) are singing nearby, warriors knew that no threat was present. These descriptions remind me of "bird language" - approaches for interpreting birds, and other animals, behaviors to further one's perceptions of their surroundings (Young 2012). By focusing on the symbolic nature of birds as messengers the authors are following a current trend in ethnoornithological research. My limited experience with bird language has increased my perception of individual birds as "non-human agents", a term the authors use in describing the relational framework they use to structure the book. While it is unclear why there is a relationship between observing bird behavior and acknowledging their agency, I think that if the field were to ethnographically investigate how "bird language" concepts are implemented in different cultures, we might develop a more nuanced understanding of birds as non-human agents. The recent review by Wyndham and Park (2019) indicates that ethno-ornithologists may include this nuanced approach in future research of birds as messengers, and if this happens the value of The Winged will increase.

The book would have benefited from additional editing. For me, the most jarring mistake was on page 36, where the heading "Doves" is missing, so one paragraph describes the qualities of cranes and the next is about doves. Once aware of this possibility, I found it easy to work around.

The laws directing how managers address the impacts on cultural and natural resources often cause them to focus on archaeological concerns when addressing Native American concerns. Managers of the Upper Missouri River area can use The Winged to identify how impacts to birds may affect Native American communities, potentially helping improve working relations. Part of my interest in reviewing this book was to see how it could be used in a course on the ethnobiology of Montana. I found it to be a good way to introduce concepts of ethnobiology and ethno-ornithology using local Montana examples. While I raised some concerns about The Winged, I found it a valuable resource for managers and educators alike.

\section{References Cited}

Scott, D. M., P. J. Weatherhead, and C. D. Ankney. 1992. Egg-eating by Female Brown-headed Cowbirds. The Condor 94:579-584.

Wyndham, F. S., and K. E. Park. 2018. "Listen Carefully to the Voices of the Birds": A Comparative Review of Birds as Signs. Journal of Ethnobiology 38:533-549. DOI:10.2993/0278-077138.4.533.

Young, J. 2012. What the Robin Knows: How Birds Reveal the Secrets of the Natural World. Houghton Mifflin Harcourt, Boston. 